\title{
Electron beam-plasma ionizing target for the production of neutron-rich nuclides
}

\author{
V.N. Panteleev ${ }^{\text {a,* }}$, A.E. Barzakh ${ }^{\text {a }}$, S. Essabaa ${ }^{\text {, }}$, D.V. Fedorov ${ }^{\text {a }}$, A.M. Ionan ${ }^{\text {a }}$, V.S. Ivanov ${ }^{\text {a }}$, \\ C. Lau ${ }^{b}$, R. Leroy ${ }^{c}$, G. Lhersonneau ${ }^{c}$, K.A. Mezilev ${ }^{a}$, P.L. Molkanov ${ }^{a}$, F.V. Moroz ${ }^{a}$, \\ S.Yu. Orlov ${ }^{\text {a }}$, L. Stroe ${ }^{\text {d, L.B. Tecchio }}{ }^{\text {d }}$, A.C.C. Villari ${ }^{\text {c }}$, Yu.M. Volkov ${ }^{\text {a }}$ \\ "Petersburg Nuclear Physics Institute RAS, 188300 Gatchina, Leningrad District, Russia \\ ${ }^{\mathrm{b}}$ Institut de Physique Nucleaire, F-91406 Orsay Cedex, France \\ "GANIL, F-14076 Caen Cedex 5, France \\ ' Laboratori Nationali di Legnaro, 35020 Legnaro, Padova, Italy
}

Available online 5 June 2008

\begin{abstract}
The production of neutron-rich $\mathrm{Ag}$, In and $\mathrm{Sn}$ isotopes from a uranium carbide target of a high density has been investigated at the IRIS facility in the PLOG (PNPI-Legnaro-GANIL-Orsay) collaboration. The UC target material with a density of $12 \mathrm{~g} / \mathrm{cm}^{3}$ was prepared by the method of powder metallurgy in a form of pellets of $2 \mathrm{~mm}$ thickness, $11 \mathrm{~mm}$ in diameter and grain dimensions of about $20 \mu \mathrm{m}$. The uranium target mass of $31 \mathrm{~g}$ was exposed at a $1 \mathrm{GeV}$ proton beam of intensity $0.05-0.07 \mu \mathrm{A}$. For the ionization of the produced species the electron beam-plasma ionization inside the target container (ionizing target) has been used. It was the first experiment when the new high density UC target material was exploited with the electron-plasma ionization. Yields of Sn isotopes have been measured in the target temperature range of $(1900-2100){ }^{\circ} \mathrm{C}$. The yields of some Pd, In and Cd isotopes were measured as well to compare to previously measured ones from a high density uranium carbide target having a ceramic-like structure. For the first time a nickel isotope was obtained from a high density UC target.
\end{abstract}

(c) 2008 Elsevier B.V. All rights reserved.

PACS: $25.40 . \mathrm{Sc} ; 28.60 .+\mathrm{S} ; 29.25 . \mathrm{Ni} ; 29.25 . \mathrm{Rrn}$

Keywords: Uranium carbide target: Ionising target; Ionization efficiency; Yield

\section{Introduction}

New projects concerning ISOL facilities of the third generation $[1,2]$ require targets containing large fractions of ${ }^{238} \mathrm{U}$. For efficient use of secondary neutron beams the density of the target material containing uranium should be as high as possible. This work is a continuation of series of off-line and on-line investigations of uranium carbide target materials of a high density $[3,4]$. The main goal of this work was to test a new high density uranium carbide target

\footnotetext{
* Corresponding author. Tel.: +7 8127136041 (Reception). +7 812 7146208 (Office); fax: +78127136041 .

E-mail address: vnp@pnpi.spb.ru (V.N. Panteleev).
}

material [3] manufactured by the method of powder metallurgy, which is available from producers in different forms (UC, $\mathrm{UC}_{2}$ ), with different dispersivity and porosity. We present the results of the first on-line tests on the production of isotopes of the elements with high ionization potentials from a new high density $\mathrm{UC}$ target material. In the first experiment we have generally concentrated on the production of neutron-rich $\mathrm{Sn}$ isotopes ionized by the electron-plasma ionization and $\mathrm{Cs}$ isotopes ionized by the surface ionization. Another task was the measurement of the yields of some hard volatile nuclides, such as $\mathrm{Ni}$ and $\mathrm{Pd}$, to establish whether isotopes of these elements (with their release process determined mainly by effusion) can be produced from the new target material. 


\section{Experiment description and results}

Historically the investigations of a high density UC target material were started in 2000, when samples of a high density rod (HDR) uranium carbide $\left(11 \mathrm{~g} / \mathrm{cm}^{3}\right.$ of uranium density) have been used for the production of neutron-rich isotopes of a large number of elements [4]. This material had ceramic-like structure with a grain size about $200 \mu \mathrm{m}$. Unfortunately, from the beginning the amount of a HDR material was limited and numerous attempts to find a producer for that kind of UC target material were unsuccessful. A new high density UC target material manufactured by the powder metallurgy method has been in use at the IRIS facility since 2005 . The first samples manufactured for on-line investigations have the following parameters: pills with the density $(12 \pm 0.5) \mathrm{g} / \mathrm{cm}^{3}$, of $2 \mathrm{~mm}$ thickness, $11 \mathrm{~mm}$ in diameter with the grain dimensions $20 \mu \mathrm{m}$. This is referred as the HDP target material.

A schematic drawing of the combined target-ion source unit utilized for the new UC target material test is shown in Fig. 1. The target material mass and the target thickness (15 pills) were $31 \mathrm{~g}$ and $10 \mathrm{~g} / \mathrm{cm}^{2}$, respectively. The surface and electron beam-plasma ionization took place inside the target container [5]. After the mass separation implanted samples were transported to a gamma-detector for the measurement of characteristic decay $\gamma$-rays. The standard procedure of the yield determination is described in [3].

In Fig. 2 the yields of neutron-rich Cs isotopes from the investigated target (open squares) and from a reference HDR target [5] (solid circles) measured at a temperature of $1900^{\circ} \mathrm{C}$ are presented. All yield values are normalized to a target thickness of $1 \mathrm{~g} / \mathrm{cm}^{2}$ and a proton beam intensity of $0.1 \mu \mathrm{A}$. The errors of the yield measurements are

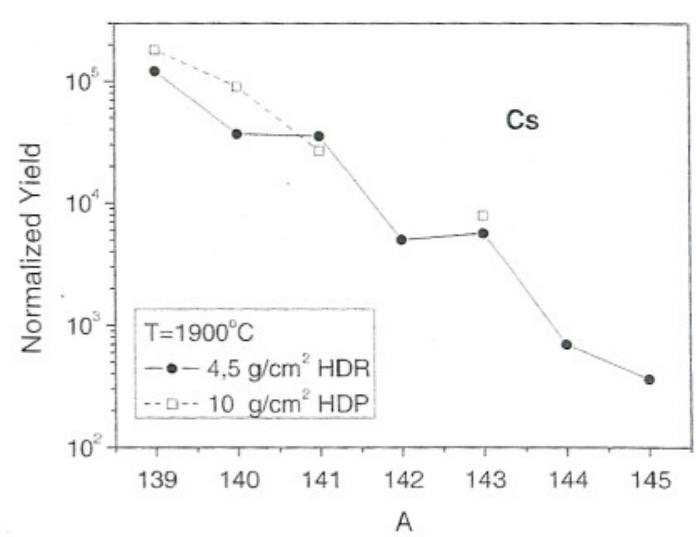

Fig. 2. Yields of neutron-rich $\mathrm{Cs}$ isotopes from the investigated HDP target (open squares) and from the reference HDR target (solid circles) measured at a temperature of $1900^{\circ} \mathrm{C}$.

$20-30 \%$ for long-lived isotopes at the maximum of the cross-section curve and $50-100 \%$ for short-lived isotopes far from stability.

The normalized yields of neutron-rich $\mathrm{Sn}$ isotopes (sum of ground and isomeric states, except ${ }^{132} \mathrm{Sn}$, which has only a ground state) are shown in Fig. 3. The target temperature was $1900^{\circ} \mathrm{C}$ as well.

The normalized yields of some other nuclides produced from the HDP target are presented in the Table 1. The temperature of the target for the production of these nuclides was $2000^{\circ} \mathrm{C}$.

\section{Discussion}

This work was the first attempt to use a new high density powder-pill target material of a rather big mass for produc-

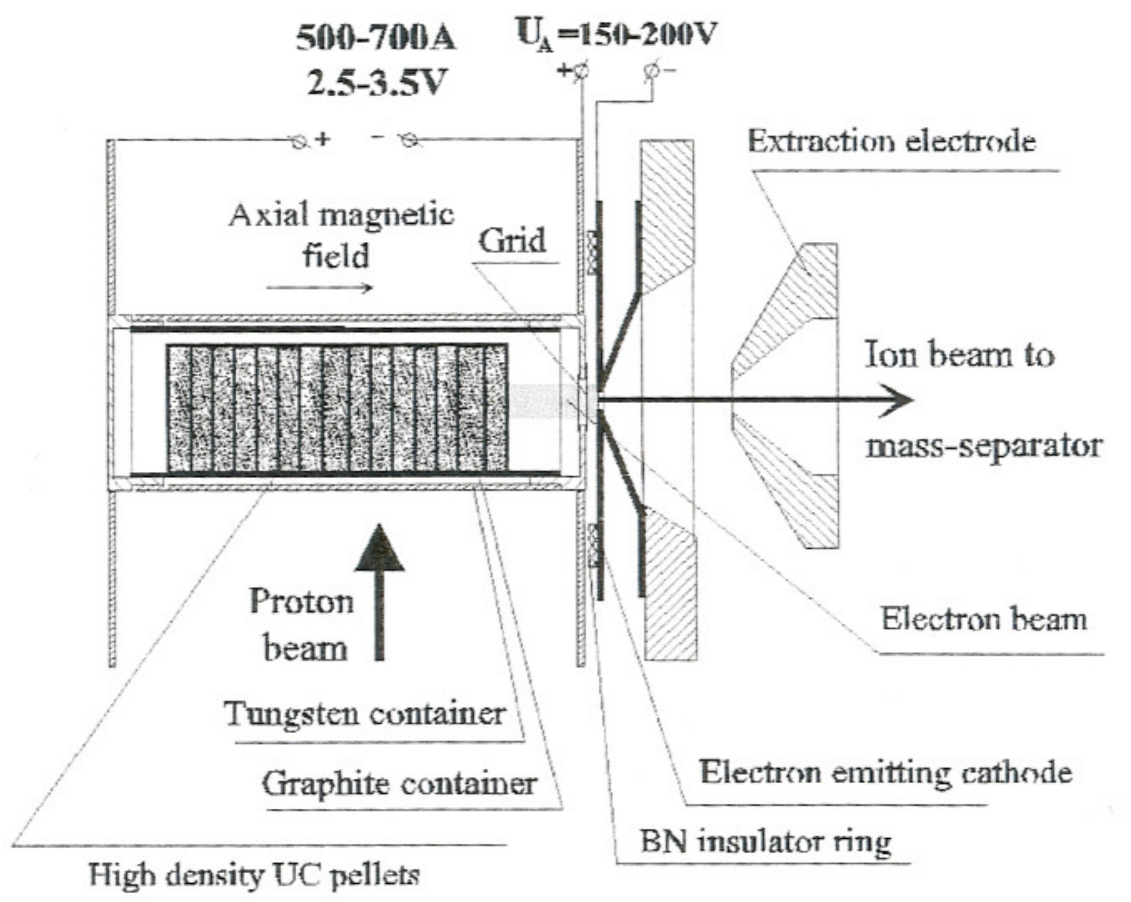

Fig. 1. Schematic drawing of the combined target-ion source unit utilized for the new UC target material test. 


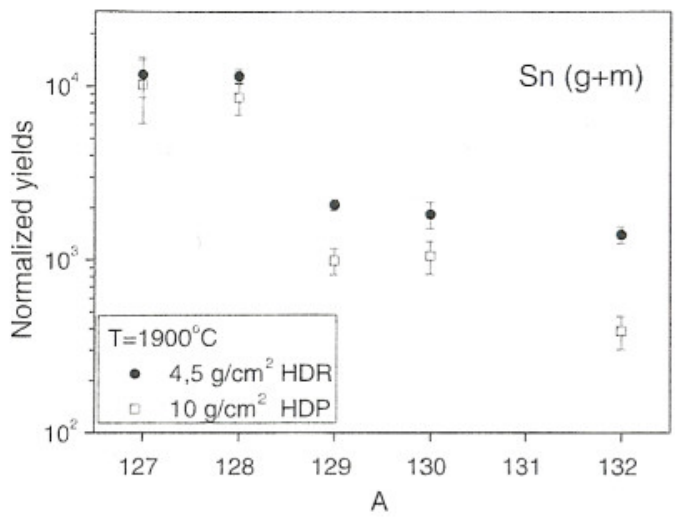

Fig. 3. Normalized yields of neutron-rich $\mathrm{Sn}$ isotopes (sum of ground and isomeric states, except ${ }^{132} \mathrm{Sn}$, which has only a ground state) obtained from HDP and HDR targets.

Table 1

Normalized yields of some nuclides produced from the HDP target

\begin{tabular}{ll}
\hline Nuclide & Normalized yield \\
\hline${ }^{65} \mathrm{Ni}$ & $9.20(2.38) \times 10^{3}$ \\
${ }^{68} \mathrm{Cu}$ & $9.07(2.02) \times 10^{2}$ \\
${ }^{69} \mathrm{Cu}$ & $4.91(1.09) \times 10^{3}$ \\
${ }^{109} \mathrm{Pd}$ & $1.03(0.21) \times 10^{3}$ \\
${ }^{119} \mathrm{Cd}$ & $1.17(0.26) \times 10^{3}$ \\
${ }^{119} \mathrm{In}$ & $9.10(1.03) \times 10^{3}$ \\
\hline
\end{tabular}

tion of isotopes of elements with high ionization potentials and also for production of some hard volatile species. In order to compare the yields of species having mainly diffusion character of release from the studied target materials, the yields of surface ionized isotopes of Cs were measured in the same temperature conditions. As one can see from Fig. 2, the normalized Cs yields from both targets are similar within the limits of the measurement errors. It shows that the efficiency of surface ionization which occurs, when atoms collide with the inner hot surface of the tungsten container, are very close for both targets. We can not present a reliable comparison of Cs release efficiency, as in this experiment the yield measurement of short-lived isotopes with $T_{1 / 2}<1 \mathrm{~s}$ has not been carried out. We can only say that there is no noticeable influence of the grain dimension decrease on the yields of isotopes with $T_{1 / 2}>2 \mathrm{~s}$. As the influence of the UC grain size on the release process is very important, experiments comparing the yield and release from uranium carbide target material of identical structure and density, but different dispersivity are required.

A comparison of the yields of $\mathrm{Sn}$ isotopes (Fig. 3) obtained from a massive HDP target and HDR target (with the mass of uranium of $6.7 \mathrm{~g}$ ) shows that the normalized yields from a new HDP target are slightly lower. It can be explained by a lower value of electron beam-plasma ionization efficiency in a HDP target due to not sufficient outgasing of the target material. The target material should be heated some hundred hours under the working tempera-

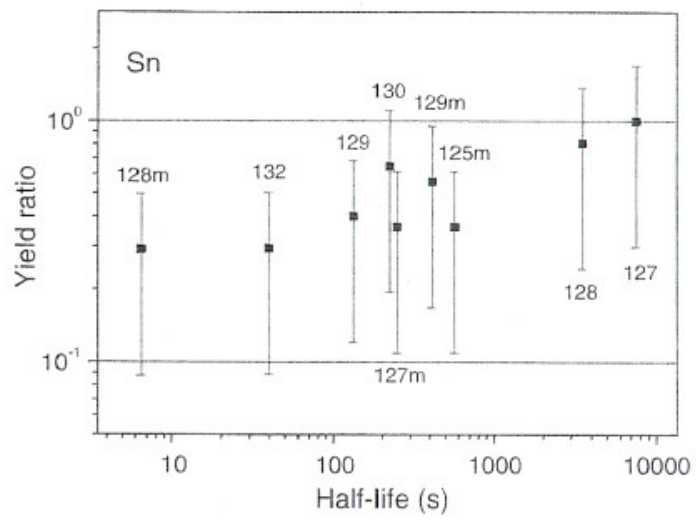

Fig. 4. Plot of the ratio of the yields of Sn isotopes (ground and isomeric states) from a HDP target to the yield of the same isotopes from a HDR target versus isotope half-lives and normalized in the point of long-lived ${ }^{127} \mathrm{Sn}$.

ture to decrease the $\mathrm{CO}^{+}$current to the value of some $\mu \mathrm{A}$. The trend of the yield of $\mathrm{Sn}$ and $\mathrm{Ag}$ (not presented here) isotopes demonstrates that there is no influence of the target material grain dimension decrease on the release speed of the produced nuclides. Fig. 4 shows the plot of the ratios of the yield of $\mathrm{Sn}$ isotopes from a HDP target to the yield of the same isotopes from a HDR target versus isotope half-lives. The ratios were normalized in the point of long-lived ${ }^{127} \mathrm{Sn}$ with the half-life $2.1 \mathrm{~h}$. Some decrease of the yield ratio for isotopes with shorter half-lives indicates that a new HDP target probably is slower than a HDR target. It can be explained by a longer effusion time for the much more massive target. For more reliable conclusions the yield measurement of $\mathrm{Sn}$ isotopes with shorter half-lives are planned. The result of production from a HDP target of such hard volatile nuclides, as $\mathrm{Ni}$ and $\mathrm{Pd}$ is rather promising, but additional work is required to increase the value of the ionization efficiency.

\section{Acknowledgements}

We acknowledge the financial support of the European Community under the FP6 "Research Infrastructure Action-Structuring the European Research Area" EURISOL DS Project contract no 515768 RIDS. The EC is not liable for the use that can be made of the information contained herein. For PNPI this work has been supported by ISTC Project No. 2965.

\section{References}

[1] A.C.C. Villari, AIP Conf. Proc. 704 (2004) 234.

[2] V.A. Nazarewicz, R.F. Casten. Nucl. Phys. A 682 (2001) 295.

[3] V.N. Panteleev, O. Alyakrinskiy, A. Andrighetto. A.E. Barzakh, M. Dubois, C. Eleon, S. Essabaa. O. Bajeat, D.V. Fedorov, G. Gaubert, A.M. Ionan, V.S. Ivanov, P. Jardin, A. Lanchais, C. Lau, R. Leroy, G. Lhersonneau, C. Mhamed, K.A. Mezilev, P.L. Molkanov, F.V. Moroz, S.Yu. Orlov, V. Rizzi, M.G. Saint Laurent, L. Stroe, L.B. Tecchio, A.C.C. Villari, Yu.M. Volkov, Eur. Phys. J. Special Topics 150 (2007) 297. 
[4] .A. Andrighetto, A.E. Barzakh, D.V. Fedorov, V.S. Ivanov, F.V. Moroz, S.Yu. Orlov, V.N. Panteleev, M.D. Seliverstov, I.M. Strachnov, L. Stroe, L.B. Tecchio, Yu.M. Volkov. Nucl. Instr. and Meth. B 204 (2003) 267.

[5] . V.N. Panteleev, A.E. Barzakh, D.V. Fedorov, A.M. Ionan, K.A. Mezilev, F.V. Moroz, S.Yu. Orlov, Yu.M. Volkov, A. Andrighetto, G.
Lhersonneau, V. Rizzi, L.B. Tecchio, M. Dubois, G. Gaubert, P. Jardin. N. Lecesne, R. Leroy, J.Y. Pacquet, M.G. Saint Laurent. A.C.C. Villari, O. Bajeat, S. Essabaa, C. Lau, M. Menna, Rev. Sci, Instr. 77 (2006) 03A705. 